International Journal of Biology, Pharmacy and Allied Sciences (IJBPAS) 'A Bridge Betueen Caboratory and QRendo'

WwW.iibpas.com

\title{
RELEVANCE OF HEALTHCARE EXPENDITURE IN HOUSEHOLDS: A
}

\section{CASE STUDY}

\section{THOMAS JOSEPH ${ }^{1}$ AND EMIN MATHEWS ${ }^{2 *}$}

1: Vice-Principal \& Assistant Professor, Department of History, Assumption College Autonomous, Changanacherry

2: MA Economics, PGDHRM, Administrative Assistant, Internal Quality Assurance Cell, Assumption College Autonomous, Changanacherry

"Corresponding Author: Emin Mathews: E Mail: eminmathews@gmail.com Received $10^{\text {th }}$ June 2021; Revised $11^{\text {th }}$ July 2021; Accepted 20 ${ }^{\text {th }}$ Aug. 2021; Available online $15^{\text {th }}$ Jan. $_{2022}$ https://doi.org/10.31032/IJBPAS/2022/11.1.1043

\section{ABSTRACT}

Health is the ability of a biological system to acquire, convert, allocate, distribute, and utilize energy with maximum efficiency. In many respects, Kerala's health status is almost on a par with that of developed economies. The state has succeeded in increasing life expectancy as well as reducing infant and maternal mortalities. The implementation of land reforms improved the standard of living of the rural poor. Kerala's achievements in health status are reflected in attainment of low infant mortality rate, low maternal mortality rate, low birth rate, low death rate, high life expectancy. The history and experience of Kerala's health and demographic transitions provide a number of lessons to other states in India and to other developing societies. The health status of Kerala can even be considered with the developed countries. The health standard of Kerala has a long tradition. Health indicator of the economy shows the standard of health status like, infant mortality, life expectancy at birth and death rates. But the main hindrance is that we are more emphasized on curative than preventive healthcare pattern. As the public health policies and programmes largely focused on curative than preventive. There were no measures been taken from part of government to control the spreading of diseases. This problem was witnessed over years. The study aims to learn to 
compare the nature and characteristics of healthcare facilities of private and public hospitals, to examine the composition and source of healthcare expenditure and to appraise the role of insurance in providing the financial aid for healthcare of the households.

\section{Keywords: Healthcare Expenditure, Health Insurance, Households, Income, Kerala}

\section{INTRODUCTION}

Health is the ability of a biological system to acquire, convert, allocate, distribute, and utilize energy with maximum efficiency. The World Health Organization(WHO) defined human health in a broader sense in its 1948 constitution as "a state of complete physical, mental, and social well-being and not merely the absence of disease or infirmity. Health is a human capital and it is considered as the personal asset of each individual. The well-being and the economic condition of a nation are determined by the health standard of its population. Healthcare is a part of social infrastructure. Availability and accessibility to health facilities is inevitable for the acceleration of the economic development of a country.

In this article we find different health aspects relating to;

1. To compare the nature and characteristics of healthcare facilities of private and public hospitals

2. To examine the composition and source of healthcare expenditure
3. To appraise the role of insurance in providing the financial aid for healthcare of the households

Key factors that have been found to influence whether people are healthy or unhealthy include the following;

Income and social status

Social support networks

Education and literacy

Employment/working conditions

Social environments

Personal health practices and coping skills

Healthy child development

Gender, Biology and genetics

Health care services

Culture

A minimum acceptable level of health standard is essential to have other benefits of life. An individual will be able to realize the full potential of his life, only if he is healthy. Health is the foundation of all productive activities. In the perspective of economics, human health is a consumer good as well as a capital good. As a consumer good it provides satisfaction to individuals who possess it enabling the consumption of other goods and services while as a capital good it generates 
income.

\section{Health}

Health is a multifaceted concept and thus it is very difficult to define it precisely.

\section{World Health Organisation}

(1948)

defines health as 'a state of complete physical, mental and social well-being and not merely an absence of diseases or infirmity'. Although this is an attractive definition, it is subjective and hard to assess (Deon Filmer, etal, 2000)

\section{World Health Organisation (1957)} defined health as a condition or quality of human organism expressing the adequate functioning of the organism in a given condition or quality of the human organism in a given condition, genital and environmental.

\section{World Health Organisation (1986)} revealed that health is not a bio-medical phenomenon, but also one, which is influenced by social, psychological, cultural, economic and political factors. This is known as psychological concept of health. Thus health is both a biological and social phenomenon.

\section{Health Scenario in India}

"Health is wealth" goes the axiom in India and it is relevant for all countries in the world. Good health is an essential requirement for the enjoyment of every aspect of life. The organized provision of services like prevention, treatment and management of illness and the preservation of mental and physical well-being may constitute a health care system.

Healthcare in India consist of a universal healthcare system run by the respective governments. Even the private sector also play role in providing healthcare. Thus the Indian economy consists of a mixed economy pattern. Public health has been described as "the science and art of preventing disease, prolonging life and promoting health through the organized efforts and informed choices of society, organizations, public and private, communities and individuals.

Over the years, India has made substantial progress in human development. However, India's overall performance on human development has been mixed in last decade. Improvements in health indicators like life expectancy and infant mortality rates have been much slower than expected. UNDP measures the achievement in the human development of any country using the Human Development Index

\section{Health Scenario in Kerala}

In many respects, Kerala's health status is almost on a par with that of developed economies. The state has succeeded in increasing life expectancy as well as reducing infant and maternal mortalities. The implementation of land reforms improved the standard of living of the rural poor. Kerala's 
achievements in health status are reflected in attainment of low infant mortality rate, low maternal mortality rate, low birth rate, low death rate, high life expectancy. The history and experience of Kerala's health and demographic transitions provide a number of lessons to other states in India and to other developing societies.

The current health status of Kerala, as levels of mortality rate and life expectancy of its population, is more akin to those of countries with much higher levels of per capita income than to those with comparable levels of income. Kerala has managed to achieve the demographic transition from high (premodern) to low (modern) birth and death ratessomething no other Indian state has been able to attain. The achievements of Kerala in health sector are even more spectacular than in education. Health indicators like life expectancy and infant mortality in the state are comparable to those in developed countries. These are the outcomes of investment in health infrastructure in all sectors, public, private and co-operative, along with people's awareness of their health needs. Kerala's health care network in the public sector under the three systems of Allopathy, Ayurveda and Homoeopathy.

\section{Household health expenditures}

Household health expenditures are the expenditures incurred by households on health care. Healthcare expenditures may be in the form of spending from savings, cash in hand, borrowing, out of pocket expenditure or by any form of insurance provided either by public or private. OOPE (Out of Pocket Expenditure) are the payments made directly by individuals at the point of service where the entire cost of the health good or service is not covered under any financial protection scheme. When an individual/household has to bear the expenditures for health care out of pocket, most of the times expenditures tend to be high in relation to their income thereby leading to low living standards (reduction in expenditure on basic necessities like food and clothing). OOPE becomes a burden for the poor especially when they have to spend huge amounts from their disposable income. And even for having an insurance coverage the individual/household has to pay a huge premium which this will also affect the consumption pattern.

\section{Health Insurance}

Insurance is a means of protection from financial loss. It is a form of risk management primarily used to hedge against the risk of a contingent, uncertain loss. Health insurance is insurance that covers the whole or a part of the risk of a person incurring medical expenses, spreading the risk over a large number of persons. Health Insurance 
constitutes health-financing schemes financed by contributions/premiums collected from individuals or governments and pooled to actively purchase services from healthcare providers either by government and/ or insurance company.

As health insurance is an important fact for providing healthcare finance the government as well as private sector provided the insurance on this. The basic health insurance schemes in India can be mentioned as follows; Social health Insurance (Central Government Health Scheme, Employees' State Insurance Scheme and Ex Servicemen Contributory Health Scheme). Government based voluntary insurance (Government Financed Health Insurance Schemes of Union and State Governments). Employer based insurance other than enterprises schemes (Private Group Health Insurance). Other primary coverage schemes (Private Individual Health Insurance). Community based health insurance.

\section{Problems in the Present Economy on Health}

The deficiencies in public healthcare activities and low opportunities for healthcare utilization by the middle and low income classes challenge the Kerala's better distribution of healthcare. Polices and the facilities promoted where not been received into hands of needy ones and this was due to the lack of awareness. The healthcare financing was a major challenging situation to all levels of households. With this back drop a close evaluation of the healthcare system at present in Kerala is required. The research question rises at this stage are; whether the household expenditure still, an out of pocket expenditure? Whether the government policies in insurance sector made any achievements in healthcare financing? And to know whether there is any significant difference between public and private healthcare services. And what all can be done to solve these issues.

\section{Structure and Relevance of Healthcare Expenditure and Health Insurance in Kerala- A Case Study}

The Kerala economy includes all type of income groups; low income, middle income and higher income groups which has a categorization of General, SC/ST, $\mathrm{OBC}$ and with BPL and APL ration cards, to find out the different income group levels. As of these reasons on huge number of groups of people the government alone won't be able to provide the healthcare, and thus the private sector came into existence of healthcare sector. But the true fact is that common people are not able to meet the financial aspect of the healthcare. This is mainly because of the curative treatment that we are taking, we do lack to take preventive measures of healthcare. The government thus implemented many financial 
support schemes for the people in form of social schemes for different income groups.

Earlier there where studies on healthcare expenditure and health insurance but till now there are no studies which together combines the healthcare household expenditure and healthcare insurance. Here the scope of study arises that as the government has implemented many financial social schemes for meeting the individual's healthcare needs. Whether these insurance schemes are being effectively transferred to the needy ones in the society or are they aware about the government schemes. And to know the whether the healthcare expenditure still an out of pocket expenditure.

The study is based on both primary data and secondary data. Primary data are collected through interview schedule to 83 households in the Vazhappally Grama Panchayat, Changanacherry-Kottayam-Kerala-India in 2018. Simple and random sampling technique is adopted for data collection.

The data collected from the respondents were scored and tabulated using Microsoft Excel and analysed using Statistical Package for Social Sciences (SPSS). Secondary data was collected from various Reports, Economic Review, Journals and Ministry of Health and Family Welfare.

An Overview of Health Scenario: India and Kerala
Health Economics is a branch of economics concerned with issues related to efficiency, effectiveness, value and behavior in the production and consumption of health and health care. Simply health economics deals with the application of the principles and theories of economics to healthcare sector. The health of the citizens in a nation improves then the development taken place. Health of a nation is actually the wealth of that nation. The role of health care is improving a nation's wealth and economic growth is well established. The purpose of healthcare services is to improve the health status of the population health care services are limited supply and demand for healthcare services.

\section{Health Scenario in India}

Over the last few decades, there has been a tremendous improvement in the quality of health care services in India. This leads to the significant improvement in health care in indicators was such as life expectancy at birth, infant mortality rate, and maternal mortality rates. In a developing country like India the public sector has a critical role in ensuring healthcare delivery to all sections of the society. public sector accounts for mere 26 percentage of the total healthcare expenditure. Indian public health spending has increased from $0.22 \%$ of GDP in 1950 - 51 to $1.05 \%$ during the mid-1980's and stagnated at a mere 
$1 \%$ of the GDP in the recently as per capita government spending is significantly lower than the other BRIC Nations.

\section{Health Statistics of India}

Almost 38 million deaths occurred due to non-communicable diseases (NCDs) each year. In that 16 million deaths occur before the age of $70 \& 82 \%$ of these premature deaths occurred in low- and middle-income countries. The World Health Organisation (WHO) indicates that India ranks very high among the nations affected by the rising wave of premature deaths caused by noncommunicable diseases, which account for $60 \%$ of all deaths in India. Non-communicable diseases, also known as chronic diseases. They are long duration and generally slow progression like cardiovascular diseases, cancers, chronic respiratory diseases and diabetes which are not passed from person to person. In India, roughly 5.8 million Indians die because of diabetes, cancer, stroke, heart and lung diseases each year. In other words, out of 4 Indians 1 has risks dying from an NCD before the age of 70. About 1.7 million Indian's deaths caused by heart diseases every year, according to the World Health Organisation.

\section{National Health Policy 2017}

India has drafted the National Health Policy twice, once in 1983 and in 2002, which has guided the approach towards the health sector in Five-Year Plans. It addresses the issues of universal health coverage, reduction in maternal mortality and infant mortality, access to free drugs and diagnosis and changes in laws to make them more relevant. The primary aim of the National Health Policy, 2017, is to strengthen and prioritise the role of the Government in shaping health systems in all its dimensions-investments in health, organization of healthcare services, prevention of diseases and promotion of good health through cross sectoral actions, access to technologies, developing human resources, encouraging medical pluralism, building knowledge base, developing better financial protection strategies, strengthening regulation and health assurance. Salient features of the National Health Policy 2017 are;

- Increase health expenditure by Government from the existing 1.15 per cent of GDP to 2.5 per cent of GDP by 2025 .

- Increase State sector health spending to more than 8 per cent of their budget by 2020 .

- Decrease in proportion of households facing catastrophic health expenditure by 25 per cent, by 2025 .

- Strengthen the health surveillance system and establish registries for diseases of public health importance by 2020 . 
- Increase Life Expectancy at birth from 67.5 to 70 by 2025 .

- Reduce under-five Mortality to 23 by 2025 and MMR from current levels to 100 by 2020 .

- Reduce neo-natal mortality to 16 and still birth rate to single digit by 2025 .

- Increase utilisation of public health facilities by 50 per cent from current levels by 2025 .

- More than 90 per cent of the new-born are fully immunised by one year of age by 2025 .

- Relative reduction in prevalence of current tobacco use by 15 per cent by 2020 and 30 per cent by 2025 .

\section{Health Scenario in Kerala}

Kerala has made significant gains in health indices such as high life expectancy, low infant mortality rate, birth rate, and death rate, etc. The State must ensure that it sustains the gains achieved. Further, the State is also facing problems of Life Style Diseases (Non Communicable Diseases) like Diabetes, Hypertension, Coronary Heart Disease, Cancer and geriatric problems. Increasing incidences of Communicable Diseases like Chikungunya, Dengue, Leptospirosis, Swine Flu etc. are also major concerns. Other than these, there are new threats to the health scenario of the State, like mental health problems, suicide, substance abuse and alcoholism, adolescent health issues and rising number of road traffic accidents. To tackle these, concerted and committed efforts with proper inter sectoral co-ordination is essential.

\section{e-Health Project}

The e-Health Project targets to link health institutions all over Kerala. The project aims to build a database of individual medical records easily accessible to the medical practitioners. It includes unique patient identification in different settings and exchange of data between different health care delivery units at primary, secondary and tertiary level across State. This could avoid the repeated medical tests and can thereby reduce rush in clinics and labs and out of pocket expenses. The scheme is envisaged to be implemented in seven districts of Kerala with Thiruvananthapuram as the pilot district.

\section{Prevention of Communicable and Non-}

\section{Communicable Diseases}

Kerala is witnessing an increasing burden of diseases, communicable \& non-communicable diseases and road traffic accidents. Although the State has been successful in controlling the communicable diseases in the past, in recent years there is a resurgence of communicable diseases leading to considerable morbidity and mortality. Strategies should focus on broad basing the preparedness for communicable and non-communicable diseases and also bringing convergence between various departments like LSG, Water Supply and Sanitation etc. The 
introduction of Health Protection Agency (HPA) is a welcome step in this regard, but the Health Protection Agency is still not operational in implementing these tasks.

Kerala, among the Indian states, has one of the highest prevalence of non-communicable disease and its associated risk factors. While the state is ranked best in terms of reduction in infant mortality rate, maternal mortality rate and high life expectancy, the prevalence of non-communicable diseases is increasing. National data shows that among rural and urban areas Kerala reported high levels of morbidity with the major chunk attributable to non-communicable diseases.

Along with communicable and noncommunicable diseases, trauma care also needs immediate attention in Kerala as Road Traffic Accidents (RTA) in Kerala have reached a crisis proportion and addressing this issue is a great challenge for health system of the state. The mortality and morbidity due to road traffic accidents in the state is very high and trauma care and emergency management system in the state currently is not fully equipped to handle this situation.

Strengthening the service delivery of public hospitals through innovative financing mechanisms

One of the most important changes in financing of the secondary/tertiary care facilities in the last few years is the introduction of insurance scheme and channelization of insurance claims to public hospitals. Currently in Kerala, government Hospitals are the main care providers of Comprehensive Health Insurance Scheme (CHIS) and the additional top up scheme CHIS Plus scheme in Kerala. The scheme mandates that the claim amount received from the insurance company should be kept in a separate account with the HMC and this money should be used for improving the service delivery in public hospitals. A gap analysis can help in understanding the current situation as well as future requirement of infrastructure and equipment for OPD, IPD, Emergency services.

\section{Strengthening Drugs and Diagnostic} Facilities in Primary, Secondary and Tertiary Facilities

The major component of out-of-pocket expenditure in the state is expenditure on drugs and laboratory tests and the strategy should aim at provision of these services in all three levels of service delivery. Presently the Kerala Medical Services Corporation (KMSCL) through centralized procurement system supplies essential medicines to all public health facilities. Further KMSCL also has retail chain outlets called "Karunya Community Pharmacy" for branded generics 
and the cost of medicines in these outlets are significantly lower than the private chemist's shops.

Thus, structural changes in health care system should aim at reduction of OOP. The principal components of cost, medicines and laboratory investigations, should be made available free at the point of delivery. Similarly, in another model HLL operates partnership models with public institutions for running and managing diagnostic services in Government Medical Collage hospitals in Trivandrum, Alleppy, Kottayam and Thrissur. Expansion of this partnership model to secondary and tertiary care hospitals can be another effective strategy in reducing out-ofpocket expenditure.

A healthy society can contribute more significantly and effectively to economic development. Long term illness and expensive illness drive non-poor into poverty. Good health is indispensible for the enjoyment of every phase of life. High levels of education especially among women and greater health consciousness have played a key role in the attainment of good health standards in Kerala. However, the issues to be addressed are the health problems of the tribal population and other marginalized communities, re-emergence of communicable diseases, second generation issues like increasing incidence of non- communicable diseases, health problems of the aged especially women and increasing health expenditure etc. The public health care system has to be strengthened further to face these challenges.

\section{Human Resource Planning in Health}

Improved work force management and manpower planning for human resources is necessary for effective delivery of health services. This would involve increasing the availability of skilled professionals, measures for recruiting and retaining staff in the rural/difficult areas, skill development and training of existing staff, and changes in the workforce management in public health system including a re-look at the existing staff pattern so as to render the service delivery more effective.

\section{Improving the Quality of Health Services}

One of the major challenges faced by the public hospitals is ensuring the quality of care in service provision. The provision of quality services requires in addition to infrastructure and human resources, proper equipment, drugs and supplies, an efficient organization of work and a high level of motivation and a consciousness about quality. Strategies should focus on how to ensure the availability of services and how to ensure inputs for assured service provision. 
In this regard the first step will be to define standards for each level of care; i.e. primary, secondary and tertiary and standardization of the existing public health facilities. The standards can be adopted from the prevailing standards like Indian Public Health Standards (IPHS) and modified according to the needs of the State. The second step in improving the quality of health services shall be accreditation of service delivery in public hospitals.

\section{Types of Health Issues in the household}

The multiple responses were given by the respondents on the types of health issues like Headache, Body pain Fever/cold, Typhoid, Fracture, Heart diseases, TB/Cancer, Diarrhea, BP, Diabetics, Knee/back pain, Asthma, Skin diseases, Body pain, Bronchitis, Other diseases. Fever/Cold is the major health issue that everyone faces. It may be because of the large number of children in each household or may be due to the changing climatic conditions of the area chosen for the survey.
Out of these 83 respondents from the survey conducted among the households in a panchayat in Kerala the results relating to the frequency of health issue on the basis of the factors regarding regularly, weekly, monthly and rarely happenings of health issues.

It was studied from the survey that out of 83 responses relating to the frequency of health issue happening in the house, the occurrence of health issue happens monthly in an average with a percent of $43.37 \%$, where $22.9 \%$ has the health issue very rarely, some of the respondents has health issues on regular basis which is $18.07 \%$, and the $15.66 \%$ of the respondents has issues on weekly basis.

\section{Reasons on Choosing Private Hospitals}

As per the survey, 53 households visit private hospitals for treatment. Here we bring in different reasons behind choosing the private hospitals for treatment even if it's commonly said that private hospitals are expensive.

\section{Frequency of health issue}

Table 1: Reasons on Choosing Private Hospitals

\begin{tabular}{|c|c|c|c|c|}
\hline \multicolumn{2}{|c|}{} & \multicolumn{2}{|c|}{ Responses } & \multirow{2}{*}{ Percent of Cases } \\
\cline { 2 - 4 } & & N & Percent & \\
\hline Private Reasons & Pvt Less Distance & 35 & $21.1 \%$ & $63.6 \%$ \\
\cline { 2 - 5 } & Pvt Proper Diagnosis & 26 & $15.7 \%$ & $47.3 \%$ \\
\cline { 2 - 5 } & Pvt High Facilities & 23 & $13.9 \%$ & $41.8 \%$ \\
\cline { 2 - 5 } & Pvt Ease Access & 21 & $12.7 \%$ & $38.2 \%$ \\
\cline { 2 - 5 } & Pvt Medicine Availability & 19 & $11.4 \%$ & $34.5 \%$ \\
\cline { 2 - 5 } & Pvt Super Speciality & 18 & $10.8 \%$ & $32.7 \%$ \\
\cline { 2 - 5 } & Pvt Nursing Care & 24 & $14.5 \%$ & $43.6 \%$ \\
\hline & Total & 166 & $100.0 \%$ & $301.8 \%$ \\
\hline
\end{tabular}

Source: Primary data

The Table 1 shows us the reasons on were given by the respondents on this as there choosing private hospitals. Multiple responses are several factors which determines the 
private hospital treatments. There were totally 166 responses on the brining out the reasons. The main reason is that the households choose private hospitals is mainly that it is of less distance and which also provides the better and proper diagnosis for the patients. It is also said that the other reasons which formulates as the private institutions provides a good nursing care and follow up and it has high facilities.

\section{Reasons on Choosing Public Hospitals}

Households also go to public hospitals for their treatment. The reasons behind choosing can be pointed out as in the below table.

Table 2: Reasons on Choosing Public Hospitals

\begin{tabular}{|c|c|c|c|c|}
\hline & & \multicolumn{2}{|c|}{ Responses } & \multirow{2}{*}{$\begin{array}{c}\text { Percent of } \\
\text { Cases }\end{array}$} \\
\hline & & $\mathbf{N}$ & Percent & \\
\hline \multirow[t]{4}{*}{ Pub reasons } & Public Less Finance & 47 & $38.2 \%$ & $88.7 \%$ \\
\hline & Public Free Medicine & 41 & $33.3 \%$ & $77.4 \%$ \\
\hline & Public Good Facilities & 26 & $21.1 \%$ & $49.1 \%$ \\
\hline & Public High Private cost & 9 & $7.3 \%$ & $17.0 \%$ \\
\hline \multicolumn{2}{|c|}{ Total } & 123 & $100.0 \%$ & $232.1 \%$ \\
\hline
\end{tabular}

Source: Primary data

Table 2 shows us the reasons on choosing public hospitals. Multiple responses were given by the respondents on this as there are several factors which determines the public hospital treatments. There were totally 123 responses on the brining out the reasons. The main reason is that the households choose a public hospital is mainly that it of less finance. other main reasons. Only $17.0 \%$ constitutes were they opt public as a reason on heavy cost burden of public hospitals.

\section{Awareness on Insurance}

Insurance is the only way to avoid the risk or burden of the health expenditure. Here we bring out whether the households are aware about the insurance schemes on health.

Free availability $b$ of medicine is one of the

Table 3: Insurance awareness

\begin{tabular}{|c|c|c|c|}
\hline & & Frequency & Percent \\
\hline \multirow{2}{*}{ Awareness } & Aware & 74 & 89.2 \\
\hline & Not Aware & 8 & 10.8 \\
\hline \multicolumn{2}{|c|}{ Total } & 83 & 100.0 \\
\hline
\end{tabular}

Source: Primary data

Awareness on insurance is an important aspect in the healthcare financing, if one is aware only they can join in the provided insurance schemes available to them. As insurance can reduce the cash burden. The above table shows the insurance awareness of people, out of 83 respondents $89.2 \%$ of the respondents is aware on insurance and only $10.8 \%$ of the respondents are not aware on insurance. The high frequency of awareness on insurance is due to the more literate people and the government as well as private awareness program showing the importance of insurance to the people in the area made this happen. 


\section{Type of Insurance}

There are many type of insurance that prevails in the society. To a greater extend it is the public agencies who are the providers of insurance with different schemes and less premium.

Table 4: Insurance Types

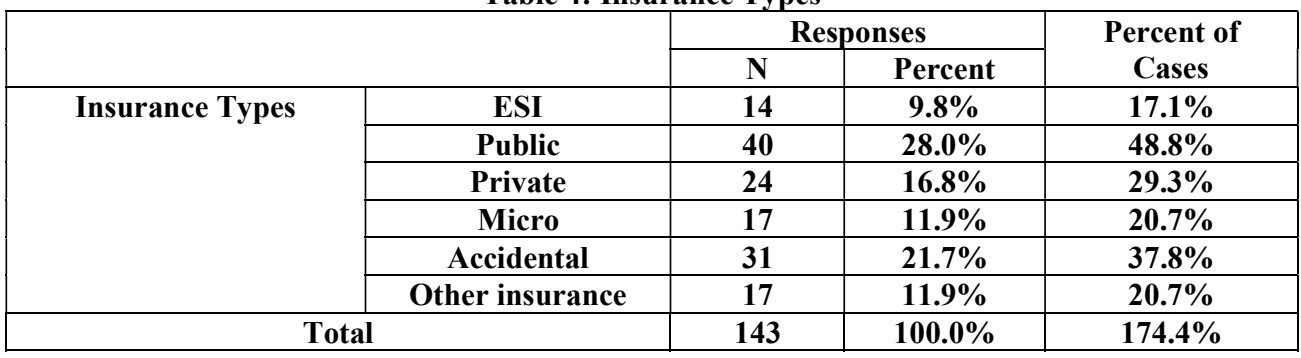

Source: Primary data

Each type of insurance has different coverages depending upon its nature. $28.0 \%$ of the respondents own public insurance schemes or public funded with a percent case of $48.8 \%$. Today most of the households have vehicle as a reason they will be forced to take accidental insurance where the $21.7 \%$ of respondents has this with a percent case of $37.8 \%$. Private insurance is hold by $16.8 \%$ with a percent case of $29.3 \%$, Micro and other insurance type constitutes $11.9 \%$ each while the percent case $20.7 \%$ is also equal for both. ESI being only responded by $9.8 \%$ with a percent case of $17.1 \%$.

\section{Government insurance schemes \& Health}

\section{Burden}

Cross tabulation helps to compare the relationship between two variables, how the variables are related to each other.

There are only 18 households who have joined in any of the government insurance schemes. 67 respondents are of the view that healthcare expenditures are always a burden on consumption of households. 15 of the respondents has the burden of health even though they are the participants of government insurance schemes. And only 3 of the households have no health burden as they have joined in insurance schemes.

52 of the respondents who are not joined in the government insurance schemes face the health burden which affects their consumption. Only 13 households don't face any health burden even though they haven't joined in any of the government schemes. This is because they don't face any health issues, may have taken proper care at the beginning time or their income level may be very high to meet all these expenses.

\section{Reasons not joining insurance schemes}

As we all know that insurance is an important need in our life. There were many respondents still not joined in any of these schemes. So we here consider the reasons for 
not joining in any insurance schemes.

Majority of the households are not able to join in any of the insurance scheme is mainly due to the lack of money. Even today the government makes much awareness on the need of health insurance; still the people do lack the proper knowledge on insurance and thus one of the reasons for not joining insurance.

Table 5: Reasons not joining insurance schemes

\begin{tabular}{|c|c|c|c|c|}
\hline & \multicolumn{2}{|c|}{ Responses } & \multirow{2}{*}{ Percent of Cases } \\
\hline & & $\mathbf{N}$ & Percent & \\
\hline \multirow{6}{*}{$\begin{array}{c}\text { Reasons not joining insurance } \\
\text { schemes }\end{array}$} & Lack of Money & 24 & $36.4 \%$ & $60.0 \%$ \\
\hline & Lack of Knowledge & 14 & $21.2 \%$ & $35.0 \%$ \\
\hline & Lack of Interest & 8 & $12.1 \%$ & $20.0 \%$ \\
\hline & Lack of Agents & 6 & $9.1 \%$ & $15.0 \%$ \\
\hline & Bad Impression & 6 & $9.1 \%$ & $15.0 \%$ \\
\hline & Others & 8 & $12.1 \%$ & $20.0 \%$ \\
\hline \multicolumn{2}{|c|}{ Total } & 66 & $100.0 \%$ & $165.0 \%$ \\
\hline
\end{tabular}

Source: Primary data

$36.4 \%$ of the respondents are of the view that lack of money is the main problem in not joining the insurance schemes and the percent case is $60.0 \%$. The other reason that the respondents pointed out is the lack of knowledge with a $21.2 \%$ while the percent case is $35.0 \%$. Lack of interest in joining the insurance is the other reason and it constitutes $12.1 \%$ with a percent case of $20.0 \%$. Lack of proper agents as a reason for not joining is being responded by $9.1 \%$ and the percent case for the same is $15.0 \%$. Bad impressions on the insurance as a reason were responded by $9.1 \%$ and the percent case for the same is $15.0 \%$, and the rest $12.1 \%$ has some other reasons with a percent case of $20.0 \%$.

\section{Major Issues on Insurance}

Even though we have insurance, there are many issues that the individual households face on insurance. And the problem of coverage on insurance, as different insurance may cover sometimes only on treatment, surgery/hospitalization or for medicines.

$26.9 \%$ of the respondents are of the view that delay in availability is the main problem that they face in insurance and the percent case is $54.4 \%$. The other reason that the $20.6 \%$ respondents pointed out is the limited coverage while the percent case is $41.8 \%$. Limited coverage means, sometimes the insurance coverages won't cover the whole need that is why the respondents face this as an issue.

Insolvency as an issue of insurance is faced by $11.3 \%$ of respondents with a percent case of $22.8 \%$. Many people are of the view that the insurance has the issue of heavy paperwork, where we have to provide many documents to take a insurance. This as an issue is faced by $14.4 \%$ of respondents while the percent case is $29.1 \%$ 
Finance is the main hindrance that every individual faces; most of the private as well as the public insurance have the problem of high premium to be paid by the insurance holders. So from the survey $20.6 \%$ of the respondents face the issue of high premium in insurance with a percent case of $41.8 \%$.

\section{Satisfaction on Insurance Support}

Insurance is needed to avoid the risk, and this risk can be avoided only if is received in the required time, more than half of the respondents i.e.; $59.0 \%$ are not at all satisfied with the insurance provided to them. Only $41.0 \%$ are the households are satisfied with the insurance provided at need time.

\section{Major Findings from the Study}

- The income of the respondents lies between 5000 and 90000, where the larger portion of the household income is being spent. As food is the basic need the major portion of income is spend for food.

- Education and health is considered as a merit good which is consumption as well as an investment good, the household income is mainly spend for this.

- As the reason on increased education it's seen that $56.6 \%$ haven't postponed their treatment.

- It was analysed that $50 \%$ of the people choose private and the remaining 50\% choose public hospital for their treatment.
- It's clear that private hospitals being rated highly than public hospitals based on its adequacy, infrastructure and medicines which are provided effectively by private.

- The choosing of public hospital is mainly due to the public less finance followed by free medicines.

- The study shows that majority of the households face different kind of health issues. $79.5 \%$ of the households face some kind of health issues is found from survey conducted.

- $36.36 \%$ of households have the health issues on an average of monthly basis.

- $43.4 \%$ of respondents have only postponed their treatment, and the main hindrance for that is the lack of proper insurance and money. The positive aspect here is that majority haven't postponed their treatment.

- The main reason for the postponed of medical treatment is the lack of money and lack of time which was made by the households.

- It was analysed that $69.9 \%$ of the respondents are of the view that health expenditure is always a burden on their consumption.

- Medicinal fee and the surgery costs are the main expenses that the respondents face as the households' expenditure. 
- Cash in hand and the insurance are the main source of money for the medical treatment as the mean value of these is high when compared with other sources.

- Around $90 \%$ of the households are aware on the need and importance of insurance.

- Government insurance schemes are provided to households.

- But only a few have been joined in the health insurance schemes, it was analysed from the survey that the main reasons for not joining insurance are, lack of money, knowledge, interest, agents and bad impression on the insurance schemes.

- It was studied from the survey that government insurance schemes are not being effectively transferred into the needy one's hand.

- Employment based and pubic insurance programs leave gaps in coverage for many families. The families in which some or all members lack insurance disproportionately include those with lower income.

- Purchasing health insurance for uninsured family members is not practical for most of these families because of their limited income and lack of assets.

- It was studied that the main issue faced on insurance is the delay in availability of the insurance at needed time. As some insurance covers only limited coverage it's also a major issue on health insurance, and the high premium on insurance are the major issues related to this.

- Even though a high percent of people has joined in insurance schemes, $59 \%$ of the households are not at all satisfied with the support given by them on their need time.

\section{CONCLUSION}

Kerala State has achieved finest basic health indicators as collated to the other states of India but confront crucial challenges of morbidity and other health inequalities. The people often compare facilities and technologies available in the public sector institutions with those available in the private sector with the obvious aftermath of adding to the dissatisfaction of the beneficiaries. The OOP expenditure on health care depends on many factors; household income, type of illness, age, sex, type of health facility and quality of care. The increased public spending on health care and increased access to health insurance can significantly reduce the OOP expenditure on health care. Moreover, it can conclude that the problem that the households faces on health issues is both increasing as well as decreasing in one hand or other. The health issues are increasing mainly due to the lifestyle problems and the healthcare facilities are also available good in number where the better treatment facilities with most modern 
technologies. The better government insurance schemes are also providing better standard of health. Even though there are some problems in health standards of healthcare in and this can only be eradicated by the government intervention and by proper awareness on people.

\section{Bibliography}

[1] Acharya, A and Ranson, K. 2005. "Health Care Financing for the Poor: Community Based Health Insurance Schemes in Gujarat." Economic and Political Weekly, Vol. 40, No. 38

[2] Achin Chakraborty. Kerala's Changing Development Narratives, Occasional paper - 5, Institute of Development Studies Kolkata Calcutta University.

[3] Ahuja, Rajeev. 2005. "Universal Health Insurance Scheme". Yojana, 49 (7): 6-8..

[4] Berman P. (1998). Rethinking health care systems: Private health care provision in India. World Development 26: 1463-79.

[5] Concept Paper on Kerala Secondary Health System Project.Dept of Health and family welfare. Govt. of Kerala, August.117, 2003.

[6] Ministry of Health \& Family Welfare (MHFW). Report of the National Commission on Macroeconomics and Health. New Delhi: MHFW, Government of India; 2005
[7] Ministry of Health \& Family Welfare (MHFW). National Rural Health Mission: Mission document. New Delhi: MHFW, Government of India; 2005.

[8] National Rural Health Mission (2012). Program Implementation Plan, Kerala. 415.

[9] Rashtriya Swasthya Bima Yojana (RSBY). 2011. "Gender Analyses." Retrieved from http://www.rsby.gov.in/Documents.aspx?I $\mathrm{D}=14$

[10] Suryanarayana M.H., Morbidity and Health Care in Kerala: A Distributional Profile and Implications, Working Paper 2008;004.

[11] WHO (2005) “Achieving universal health coverage: Developing the health financing system" technical brief for policy -makers.

[12] http://iib.gov.in/IRDA/healthpub/Health_0 910.pdf

[13] http://spb.kerala.gov.in/EconomicReview2 016/web/index.php

[14] https://kerala.gov.in/documents/10180/ad4 30667-ade5-4c62-8cb8-a89d27d396f1

[15] Sajja, G., Mustafa, M., Phasinam, K., Kaliyaperumal, K., Ventayen, R., \& Kassanuk, T. (2021). Towards Application of Machine Learning in Classification and Prediction of Heart Disease. 2021 Second International Conference On Electronics And Sustainable Communication Systems 
(ICESC).

https://doi.org/10.1109/icesc51422.2021.9 532940

[16] Veluri, R., Patra, I., Naved, M., Prasad, V., Arcinas, M., Beram, S., \& Raghuvanshi, A. (2021). Learning analytics using deep learning techniques for efficiently managing educational institutes. Materials Today:
Proceedings.

https://doi.org/10.1016/j.matpr.2021.11. $\underline{416}$

[17] C.M. Thakar, S.S. Parkhe, A. Jain et al., 3d Printing: Basic principles and applications, Materials Today: Proceedings, https://doi.org/10.1016/j.m atpr.2021.06.272 